IZA DP No. 10322

Couples' Retirement under Individual Pension Design: A Regression Discontinuity Study for France

Elena Stancanelli

October 2016 


\title{
Couples' Retirement under Individual Pension Design: A Regression Discontinuity Study for France
}

\author{
Elena Stancanelli \\ Paris Jourdan School of Economics, \\ CNRS and IZA
}

Discussion Paper No. 10322

October 2016

\author{
IZA \\ P.O. Box 7240 \\ 53072 Bonn \\ Germany \\ Phone: +49-228-3894-0 \\ Fax: +49-228-3894-180 \\ E-mail: iza@iza.org
}

Any opinions expressed here are those of the author(s) and not those of IZA. Research published in this series may include views on policy, but the institute itself takes no institutional policy positions. The IZA research network is committed to the IZA Guiding Principles of Research Integrity.

The Institute for the Study of Labor (IZA) in Bonn is a local and virtual international research center and a place of communication between science, politics and business. IZA is an independent nonprofit organization supported by Deutsche Post Foundation. The center is associated with the University of Bonn and offers a stimulating research environment through its international network, workshops and conferences, data service, project support, research visits and doctoral program. IZA engages in (i) original and internationally competitive research in all fields of labor economics, (ii) development of policy concepts, and (iii) dissemination of research results and concepts to the interested public.

IZA Discussion Papers often represent preliminary work and are circulated to encourage discussion. Citation of such a paper should account for its provisional character. A revised version may be available directly from the author. 


\section{ABSTRACT \\ Couples' Retirement under Individual Pension Design: A Regression Discontinuity Study for France*}

Retirement policies are individually designed but the majority of people of retirement age live as couples. We estimate the effects of a French pension reform on spouses' employment decisions. We use labor-force survey data, pooled over different years, on fifty thousand French couples and apply a regression discontinuity framework, also controlling for couple's unobserved heterogeneity. We conclude that the reform immediately reduced both spouses' retirement probability. The wife's retirement probability also drops by 1 to 4 percentage points if the husband is hit by the reform, and vice-versa. Instrumenting spousal retirement with legal retirement age, own retirement probability rises by 2 to 6 percentage points upon spousal retirement.

JEL Classification: J14, C1, C36, D04

Keywords: ageing, retirement, policy evaluation

Corresponding author:

Elena Stancanelli

Paris School of Economics

Maison des Sciences Economiques

106-112 Boulevard de l'Hopital

75013 Paris

France

E-mail: elena.stancanelli@univ-paris1.fr

\footnotetext{
* The first version of this research, entitled "Spouses' Retirement and Hours Outcomes", was previously circulated as IZA DP 6791. I thank for comments participants at the American Economic Association at San Francisco, a NETSPAR conference in Amsterdam, a SOLE conference in Boston, a French applied economics conference in Nice, and seminars at the Universities of Aarhus, Siena, Padua and Verona. This project received funding from the European Union $7^{\text {th }}$ Framework Program for research technological development and demonstration under grant agreement no. 613247 for the research project titled AGENTA. I am also grateful to the Network for Studies on Pensions, Aging and Retirement for financial support. Any errors are mine.
} 


\section{Introduction}

Increasing individual working lives to counter population ageing and public pension deficits is currently of great interest to policy makers. Most OECD countries have implemented policies to make individuals work longer, and in particular many have increased the legal retirement age. France was a pioneer in this area. The reform we analyze here was voted on by the government in the summer of 1993. In France like most other countries, retirement laws and pension benefits are individually designed (Gruber, Jonathan and David Wise, 2005), while the vast majority of individuals of retirement age live as couples and very likely plan their retirement together (Michael Hurd, 1990; David Blau, 1998; Mark An, Bent Jesper Christensen and Nabanita Datta Gupta (2004), Bo Honoré and Aureo de Paula, 2014). ${ }^{1}$

Leisure complementarities are generally considered as one of the main drivers of 'joint retirement', the fact that spouses retire often within a year from each other (Maria Casanova, 2010; Mark An, Bent Jesper Christensen and Nabanita Datta Gupta, 2004; Gustman and Thomas Steinmeier, 2000; Michael Hurd , 1990). Recent work though highlights asymmetries in spouses' retirement strategies. Robert A Pollak (2013) argues that spouses may have conflicting interests over the timing of retirement because of age differences and gender differences in life expectancy as well as the social security design. Age differences between spouses may not be exogenous to household decision-making as they may capture 'marriage mismatch' (Pierre-Andre Chiappori, Sonia Oreffice and Climent Quintana Domeque, 2012) with the older spouse may, for example, compensate by working longer hours in the market (Hans Bloemen and Elena Stancanelli, 2015). Gustman and Thomas Steinmeier (2009) incorporate partial retirement strategies in a discrete choice model of spouses' retirement to conclude that in numerous situations individuals in a couple may decide to retire only if their spouse does not retire. Using data drawn from the Health and

\footnotetext{
${ }^{1}$ Wilbert Van der Klaauw and Kenneth Wolpin (2008) also provide structural models of household retirement.
} 
Retirement Study (HRS), they find that the increased labour force participation of American women has actually contributed to lower husbands' hours of market work. To date there is also a bulk of controversial evidence on the effect of social security design on spouses' retirement decisions. For example, Courtney Coile (2004) finds that both American spouses have similar participation responses to own financial and social security incentives but while the husband also reacts to the wife's (cross) incentives the opposite is not true. Donna Gilleskie and David Blau (2006) put forward a dynamic model of couples' retirement decisions accounting for health insurance, to conclude for differential responses of husbands and wives. Kanika Kapur and Jeannette Rogowski (2007) investigating the effect of employer-provided retiree health insurance on the retirement behaviour of dual-earners in the USA, find evidence of asymmetric effects for partners: the wife's health insurance increases joint retirement while the husband's does not. David Blau (1998) concludes that eliminating dual entitlement to social security benefits would have a significantly positive effect on the labour supply of married women and a negative one on husbands' labour supply, though both effects would be small. Michael Baker (2002) found somewhat more symmetric responses of partners, concluding for a negative effect of a new allowance for dependent spouses on the participation rates of eligible Canadian women and their husbands.

The current paper represents the first attempt to open the black box of spouses' retirement strategies in France, as the earlier literature focused on the individual retirement decision. ${ }^{2}$ As is the case in the U.S. the majority of couples in France are dual-earners, and most married women work full-time. The labour-force participation rates of French women and men aged 45 to 54 have been slightly above those of their American counterparts (Francine

\footnotetext{
${ }^{2}$ Jean-Olivier Hairault, Francois Langot and Thepthida Sopraseuth (2010) model the employment effect of the distance to legal retirement age in France, in a theoretical job-search framework, to conclude that increasing legal retirement age is likely to increase the employment rates of older workers. Luc Behagel, Didier Blanchet and Muriel Roger (2014) provide a comprehensive picture of individual retirement patterns in France. Beatrice Sedillot (2002) provides descriptive evidence of interactions in spouses' retirement decisions in France.
} 
Blau and Lawrence Kahn, 2013), since, respectively, the 1990s and the 2000's (see Figure 1). There are no spousal pension benefits and public retirement (defined-benefit) pensions are the rule in France. Only a tiny minority of workers receive an employer-provided pension (6\% according to Lans Bovenberg, 2011) in addition to their public pension. Replacement rates of pension benefits to previous earnings vary between $50 \%$ and $80 \%$ depending on the sector of employment and the time of retirement. Periods of inactivity (maternity leave, sickness, and unemployment) are all fully insured with pension rights. Health insurance (which often appears as a concern in the earlier literature as it affects older spouses' employment behavior) is universally public in France. Therefore, it is possible to neatly identify the effect of retirement policy changes on the retirement decision of husbands and wives, as there are a priori no other confounding factors.

Retirement is an "absorbing" state: only $1 \%$ or less of older spouses report positive hours after having retired from work. Thus, we focus on the retirement decision. Studying the employment decision would lead to equivalent conclusions. The retirement policy that we analyze here required individuals born in 1934 or later to contribute three extra months to the social security fund, for each year of birth after 1933, up to a maximum of ten extra quarters, in order to retire with "maximum" pension benefits. We exploit information on own and spouse's date of birth to apply a sharp regression-discontinuity design of the effect of the reform on both spouses' retirement. As husbands are on average twenty-four months older than wives, we can estimate both the direct and indirect (via the spouse) effects of the reform (using 24-month or 48 month bandwidths on each side of the cut-off). Regarding anticipations, the reform was voted on in the summer of 1993 and implemented in January 1994, which leaves little scope for individuals to react before its coming into force.

We conclude that spouses affected by the reform postpone their retirement significantly: the immediate probability of retirement dropped by about 2 percentage points for the husband 
and by about 4 percentage points for the wife. The reform also affected the spouse's decision to retire: the own retirement probability drops by 1 to 4 percentage points when the spouse is affected by the reform. We also conclude that the husband's retirement probability increases by about 5 percentage points upon the wife's retirement (instrumented with legal retirement age) while the wife's increases by about 2 percentage points upon retirement of the husband. In contrast, the estimated jump in own retirement probability at age 60 is 32 to 35 percentage points for the husband and 25 to 27 percentage points for the wife. Combing the social security laws on eligibility to maximum pension benefits (changed by the 1993 reform) with the legal retirement age to instrument each spouse's retirement, we obtain similar estimates: spousal retirement increases own retirement by about 1 to 3 percentage points against a jump in own retirement by 30 to 40 percentage points at own treatment.

The structure of this paper is as follows. The next section describes the empirical approach. The institutional background is presented in Section 3. The data are detailed in Section 4. The graphical analysis and the results of estimation are then discussed in Sections 5 and 6, respectively. The last section draws some conclusions.

\section{The method}

The household utility function can be seen as a weighted average of the utility of each spouse with the weights representing the bargaining power of each spouse (see, for example, Olivier Donni, 2008, for a review of household economics models). Under this set up, distribution factors (such as changes in public policies) may affect the weight of each spouse and thus, their say in the household decision process. Spouses maximize the household utility function subject to a budget constraint that depends on each spouse's labor income and non-labor income, including also pension income. Spouses retire if the household expected utility under their retirement is larger than the household expected utility if they do not retire from work. 
In the literature, leisure complementarities have been described as one of the main drivers of spouses' joint retirement strategies, the fact that spouses retire within a year from each other. Most models of retirement focus on individuals (Gruber, Jonathan and David Wise, 2005). The identification challenges of structural models of household retirement are non-negligible, as the decision to retire depends on individual (and spousal) health, wealth and income as well as expectations of these variables and the social security rules. ${ }^{3}$ Here we take an empirical approach.

The reform we consider here affected individuals born after December 1933. The reform was voted on in July 1993 and implemented in January 1994. We exploit this natural experiment, as individuals born just before or just after January 1934 are likely to be very similar in every other respect so that we can isolate the effect of this reform on their retirement decisions. Given that spouses are on average two years apart, we can estimate both the direct (on the own retirement probability) and indirect effect of the reform (via changes in the retirement probability of the spouse).

Using a Regression Discontinuity (RD) approach has a number of advantages over the differences-in-differences models (Guido Imbens and Thomas Lemieux, 2007; Wilbert Van der Klaauw, 2008; David Lee and Thomas Lemieux, 2010) that have been widely used in most empirical work on the effects of public policies on spouses' retirement strategies. ${ }^{4}$ Essentially, as individuals who are close to the discontinuity cut-off (here, being born in 1934) on the opposite sides of this cut-off are likely to be very similar, a regression discontinuity is very close to an experimental design. On the other hand, the drawback is that we can only estimate the immediate effect of the reform. We can here apply a regression discontinuity as there are no other policies that specifically affected individuals born after

\footnotetext{
${ }^{3}$ Wilbert Van der Klaauw and Kenneth Wolpin (2008).

${ }^{4}$ Erich Battistin, Agar Brugiavini, Enrico Rettore and Guglielmo Weber (2009) were the first to apply a RD design to study the effect of household head's retirement on household consumption.
} 
December 1933. Regarding anticipations (David Lee and Thomas Lemieux, 2010), while birthdate (or age) certainly cannot be manipulated, individuals do know their age (and their birthday) and could therefore behave differently in anticipation of the reform, which would invalidate the natural experiment design. However, since the policy was announced and voted on only 6 months before its introduction, this seems unlikely. We use the McCrary approach to test for the continuity of the running variable.

We denote by $\mathrm{O}$ the outcome variable. The treatment is given by the 1993 policy reform, which affected individuals born after December 1933, who were treated as from January 1994. Our goal is to estimate the average impact of the treatment on spouses' outcomes:

1) $\left.\gamma=\mathrm{E}\left[\mathrm{O}_{(1}\right)-\mathrm{O}_{(0)}\right]$

We assume that any difference in outcomes is due to the treatment, knowing that we may only observe $\mathrm{O}$ for the same spouse $\mathrm{j}$ either before $(0)$ or after $(1)$ the treatment. Assuming the continuity of $\mathrm{E}[\mathrm{O}]$ on either side of the cut-off, and defining the running variable, $\mathrm{M}$, as the difference in months between the individual birthday and the $1^{\text {st }}$ January 1934 , the RD estimator $\gamma_{\mathrm{RD}}$ can be rewritten as:

2) $\gamma_{\mathrm{RD}}=\lim _{\mathrm{M} \rightarrow 0}^{-} \mathrm{E}\left[\mathrm{O}_{\mathrm{j}(1)} \mid \mathrm{M}_{\mathrm{j}}=0\right]-\lim _{\mathrm{M} \rightarrow 0}^{+} \mathrm{E}\left[\mathrm{O}_{\mathrm{j}(0)} \mid \mathrm{M}_{\mathrm{j}}=0\right]$

which can be approximated (Hahn, Jinyong; Petra Todd; Wilbert Van der Klaauw, 2001; Imbens, Guido and Thomas Lemieux, 2007) by taking the difference of the mean outcomes of the respondents born in the months close to (before and after) the treatment (the cutoff point of being born in January 1934). Assuming a linear regression model for the outcome, we can also write:

3) $O_{j}=\gamma_{R D} T_{j}+\lambda f\left(M_{j}\right) T_{j}+\beta f\left(M_{j}\right)\left(1-T_{j}\right)+u_{j}$ 
Where $\mathrm{T}$ is the (which equals one for individuals born in January 1934 and later months, and zero for those born in the months before January 1934), $f\left(M_{J}\right)$ is a linear function of the difference in months between the individual birthday and January 1934, interacted with the treatment dummy $\mathrm{T}$ to allow for different effects on either side of the cutoff. We estimate $\gamma_{\mathrm{RD}}$ using a fully non-parametric approach (specifying local polynomials with a triangular kernel, as in Austin Nichols, 2014), as well as linear regression models. We use the same bandwidth for both models. We apply the procedure as in Sebastian Calonico, Matias D. Cattaneo and Rocio Titiunik (2014) to determine the optimal bandwidth, which produces an optimal bandwidth of 48 months for the RD impact of the reform on the wife's retirement probability and a slightly different figure (36 or 41) for the other RD specifications; we opt to present results using the same bandwidth for all the RD specifications. The results are in general robust to using different bandwidths. We separately estimate each spouse's response to both own treatment and spousal treatment ("cross-effects" or "spillovers" or "indirect" effects). To account for the rotating sample structure (where most couples are observed more than once, and up to three times over the sample period) we cluster the errors at the couple level. In addition, to control for couple-specific characteristics, including notably the age difference between the spouses, we also estimate a variant of these models allowing for couple random effects. We also experiment with allowing for multiple treatments ${ }^{5}$ by considering two cutoffs: one for the husband's been born in 1934 or later and the other for the wife's been born in 1934 or later. The husband is on average 24 months older than the wife in our sample. Then, the bandwidth is such as to include couples in which both the husband and the wife were born within 48 months from January 1934. These models provide us with an estimate of the Intent-to-Treat (ITT) impact of the reform on the retirement decision of couples in which both spouses were born between 1934 and 1938, the control group being couples in which

\footnotetext{
${ }^{5}$ The state of the arts for multiple regression discontinuity applications is still evolving as accounted in Matias Cattaneo, Luke Keel, Rocio Titiunik and Gonzalo Vazquez-Bare (2014).
} 
individuals were born between 1930 and 1934. Our conclusions are robust to considering only couples in which both spouses were born within 2 years (or even within 6 years) from 1934.

As an additional check for the extent of the interactions of spouses' retirement decisions, we exploit the legal retirement age of 60 at which most French workers retire with "maximum" pension benefits and estimate the effect of spousal retirement (instrumented by being aged 60 or more) on own retirement. This is equivalent to specifying a Fuzzy Regression Discontinuity model here. As the legal retirement age can be anticipated, individuals may react in advance of their (spouse) reaching legal retirement age. However, both spouses are bound by the legal retirement age and on average the husband is two years older than the wife. Since the wife cannot retire before 60 , the husband may then opt for retiring a little later, though his pension income would not increase by staying longer on the job (see Section 3). Therefore, we argue that legal retirement age can be exploited to instrument spouses' retirement. There are no other policy measures that affect individuals upon reaching age 60 in France. Under this set up, the spouse $\mathrm{j}$ being aged 60 on the day of the survey interview is the 'cut-off' for the treatment of spouse i, $S_{\mathrm{i}}$, with Age equal to the age of spouse $\mathrm{j}$ minus 60 (which is equal to zero at the cut-off). Given the continuity of the running variable (the age of spouse $\mathrm{j}$, which we measure in months and fractions of months), the FRD estimator can be rewritten as:

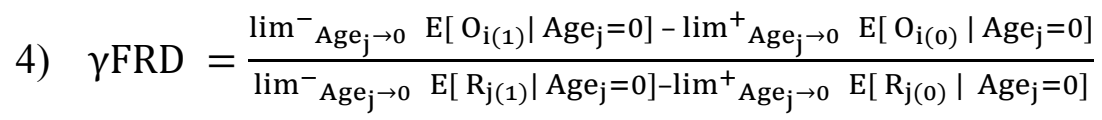

We can then use a local polynomial approach to estimate $\gamma$ FRD or a two-stage least square (2SLS) approach -which is equivalent to a fuzzy RD design (Jinyong Hahn, Petra Todd and Wilbert van der Klaauw, 2001) - and write each spouse's outcome, $\mathrm{O}_{\mathrm{i}}$ as a function of the other spouse's retirement probability, $R_{j}$, instrumented with a dummy, $S_{j}$, which takes the 
value of one when spouse $\mathrm{j}$ has reached age 60 (720 months or 21840 days) of age- and zero otherwise, as follows:

5) $O_{i}=\mathrm{a}^{\mathrm{i}}+R_{j} \mathrm{i}^{\mathrm{i}}+\left(1-\mathrm{S}_{\mathrm{j}}\right) * \mathrm{Age}_{\mathrm{j}} \mu^{\mathrm{i}}+\mathrm{S}_{\mathrm{j}}{ }^{*} \operatorname{Age}_{\mathrm{j}} \check{\mathrm{n}}^{\mathrm{i}}+\mathrm{v}_{i}$

6) $R_{j}=a^{r j}+S_{j} \gamma^{r j}+\left(1-S_{j}\right) A g e_{j} \mu^{r j}+S_{j} A g e_{j} \check{n}^{r j}+v^{r j}$

where Greek letters denote the parameters to be estimated, Age $\mathrm{j}_{\mathrm{j}}$ is a linear term (or first degree polynomial) in age of the spouse $j$ (normalized by subtracting 60), and we also allow for interactions between $S$, the age cut-off dummy, and the age polynomial, as is normal (Joshua Angrist and Jorn-Steffen Pischke ( 2009, page 261). The empirical strategy here be seen as a FRD or an instrumental-variable approach. The literature typically recommends wider bandwidths in fuzzy regression discontinuity designs than in the case of sharp regression discontinuity. We control for couple fixed effects (or, alternatively, random effects). Again, we check the robustness of our conclusions to allowing for multiple treatment of each spouse by running a linear regression model of own retirement with two cut-offs for both spouses' being aged 60 and above (Table 5). This provides us with an estimate of the Intent-to Treat (ITT) impact of the legal retirement age law on the retirement decision of couples.

Finally, we combine the two requirements of being aged 60 and having paid enough social security contributions to be able to retire with "maximum pension benefits", to define the treatment. To do so we construct a measure of each spouse's "potential" pension contribution records. The details are given when reporting the results of estimation of this specification, at the end of Section 6. This provides us with estimates of Intention to Treat (ITT) impact of retirement laws on spouses' retirement decision. The treatment group is made up of individuals that can potentially retire with maximum pension benefits (they are aged 60 and based on their education completion and age we expect them to have worked enough to be 
able to retire with the maximum level of pension benefits). Their probability to retire is greater than zero but less than one, as non-compliance is possible. The control group does not yet have reached legal retirement age and/or has not yet worked enough to be able to retire with maximum pension benefits. Our goal is to capture interaction effects within the couple's retirement decisions, by instrumenting the retirement decision of each spouse with retirement laws. Under this framework, we do not focus specifically on individuals affected by the 1993 reform, but they are included in the sample. Therefore, individuals may be able to anticipate the treatment and change their retirement behavior in anticipation of that too, but based on empirical observation we do not find evidence of anticipation.

\section{Institutional Background}

Most workers in France retire by the time they are aged 60: age 60 is the 'effective' retirement age according to recent $\mathrm{OECD}$ estimates $(\mathrm{OECD}, 2014)$. This is unsurprising as 60 is the legal age at which most workers in France can retire with "maximum" pension benefits. In 2010, this legal retirement age threshold was raised from 60 to 62, but with effect only in 2018. The age 60 threshold thus still currently applies, and we do see a large increase in both spouses' retirement probability at age 60 (the top panel in Figure 6). Particular sectoral agreements enable some workers to retire before 60 , with "early" retirement often being at age 55, but these apply to only a minority of workers (we find no jump in retirement at age 55 for either the husband or the wife: see the top panel of Figure A in the Appendix). By age 65, the law also requires most workers to retire if they have not yet done so. ${ }^{6} \mathrm{We}$ can therefore think of the French retirement system as a two legal retirement-ages system, with a first threshold at 60 and a second at 65, although in practice the vast majority of workers retire long before 65 (there is no jump in retirement at 65 for the husband: see the bottom panel in

\footnotetext{
${ }^{6}$ The 2010 reform also raised this age 65 threshold with effect as from 2018.
} 
Figure A in the Appendix). This likely reflects that pension benefits do not increase any further with employment after age 60 when individuals have sufficient years of socialsecurity contributions.

According to recent estimates, about 79 per cent of French retirees claim only a public (first pillar) pension, while 6 per cent also receive an occupational (employer-provided) pension and 18 per cent also have a private pension. The corresponding American figures are, respectively, 45, 13 and 42 per cent (Lans Bovenberg, 2011). The replacement rates of pension benefits with respect to past earnings are quite generous, and vary roughly between 50 per cent and 80 per cent or more. Pension benefits are a function of past earnings with a maximum level that depends on workers' social-security records and varies according to the year of birth (since the 1993 reform) and the sector of employment. For example, a privatesector worker born in 1943 who entered the labor market at age twenty would have to work until 60 to retire with maximum pension benefits - knowing that this pension benefit (adjusted for inflation) would be received every month from retirement until death.

The key to understanding the retirement mechanism in France is that pension benefits do not rise if individuals continue to work once they have worked long enough to receive maximum pension benefits: the private-sector worker in our example would receive the same monthly pension benefit retiring at 60,61 or even later. Retiring at the legal retirement age of 65 is interesting for workers that have interrupted careers (often the case for married women) or that entered labor the labor very late (like doctors) as those retiring at age 65 become eligible for maximum pension benefits regardless of the length of their contribution period. ${ }^{7}$ For example, if the private worker of our example only started working at age 30 , s/he would be able to retire with maximum pension benefits at age 65; while the drop in pension income for retiring earlier than 65 would be substantial (the replacement rate would drop by 15 to 20

\footnotetext{
${ }^{7}$ These rules are undergoing a reform nowadays.
} 
percentage points if s/he retired at age 60). Indeed, we find a jump into retirement at age 65 for some of the wives but not for the husbands (bottom panel in Figure A in the Appendix).

The 1993 retirement reform, which was voted on in the summer of 1993 and came into force in January 1994, increased the length of the maximum contribution period required to retire with maximum pension benefits for workers born in 1934 or afterwards. The number of extra contribution months varied according to the distance between the birth date and the "cutoff" point of being born in 1934. While those born in 1934 needed an extra three months of work history, those born in 1935 needed six more months, and those born in 1943 or later 30 extra months. Treatment intensity is thus proportional to the distance from the cutoff. In line with the discussion above, not contributing these additional months would entail an income penalty, as workers retiring earlier would not be able to receive the maximum level of pension benefits (the replacement rate of pension benefits to past earnings would drop accordingly). The rules for the calculation of maximum pension benefits were also made tighter, introducing a longer reference period for the earnings which would serve as the reference earnings to calculate pension benefits - by lengthening the reference period, less weight is given to the highest earnings, which are often earned late in the career. Therefore, the reform provided incentives for individuals to retire later. Because breaks in employment not insured with pension contributions are often chosen by the individual, using the actual contribution period as the running variable (instead of the individual birthday) did not appeal to us (besides, this measure is not available in the LFS) but we experiment with constructing a measure of "potential" contributions and interact it with the legal retirement age (see Section 6, last subsection). 


\section{The data}

Our analysis data come from the French Labour Force Surveys (LFS). We chose this sample for a number of reasons. First, administrative social security data in France are only available at the individual level to date and do not allow to identify or link same-household members. The census data are cross-sectional and only collected every ten years. The 1990-2002 LFS surveys are annual with one-third of the sample exiting each year and being replaced by new members (three-year rotating panel). These surveys are very comparable over time, as they use the same questionnaire, data-collection method (personal interviews at the respondent's home) and sample design. The response rate was almost 90\%. This LFS series was broken though in 2003 to comply with Eurostat requirements. The newer LFS series (from 2003) relies on quarterly surveys, mostly carried out by telephone; and the questionnaire and sample design differ from the earlier 1990-2002 surveys. In addition, another reform regarding the duration of pension contributions took place in 2003, exactly at the time of the LFS series break. We thus analyze a sample of couples in 1990-2002 LFS data as follows:

- Individuals were matched to their partner if any and single people were dropped from the sample. ${ }^{8}$

- Multi-couple households were dropped.

- Records from different survey years were then pooled together.

This produced a sample of 588654 couples, including cohabiting couples (who are, however, only a very small minority among older spouses: our results are robust their exclusion). The sample size in the empirical analysis varies according to whether we focus on the "husband" being born in January 1934 as the cut-off or the "wife" being born in January 1934 (we call

\footnotetext{
${ }^{8}$ In this survey, it is not possible to distinguish same-sex couples from singles sharing housing, as same sex individuals are automatically coded as singles.
} 
the male partner the "husband" and the female partner the "wife" regardless of marital or cohabiting status) or whether we concentrate on the legal retirement age and set the cut-off at the husband (or the wife) having reached the legal retirement age of 60 . The sample size is over 50,000 couples in all empirical specifications when setting an (optimal) bandwidth of 48 months, either for the distance in months from being born in January 1934, or the distance in months from being aged 60 , and for either spouse. We can carry out panel analysis on a sample of over 30,000 couples that are observed at least twice and at most three times, over the sample period. Attrition does not seem to be a major problem as only $5 \%$ of the sample is not re-interviewed at least a second time. Some of this attrition could possibly be associated with the couple changing address upon (joint) retirement (as the survey does not follow households that move), but the McCrary test performs well, suggesting that this is not a systematic problem (Stancanelli, 2012).

The LFS collects month and year of birth together with the day, month and year of the interview. We can therefore construct a continuous measure of month and year of birth and the distance in months from being born in January 1934. We also construct a continuous measure of age (in months and fraction of months) at the day of the interview. The retirement status is subjectively assessed by the individual and measured on the interview date. In particular, the individual reports whether his/her main economic status was employment, unemployment, full-time education, military service, retirement, being a housewife or other inactive. Retirement is an absorbing state in France, which means that considering employment as the outcome variable, would not affect our conclusions. Only under 1 percent of men and about 0.3 percent of women who report retirement also report positive hours of work in our sample.

We do not control for other explanatory variable in the empirical analysis, but check that other variables do not change discontinuously for individuals born in 1934 (or aged 60), as is 
customary in RD analysis. These variables (Table A in the Appendix) include completed years of education, the local unemployment rate, the number of children.

\section{Graphical analysis}

A number of insights into the validity of the empirical design and the effects of the treatment can be obtained by simply plotting the data (Guido Imbens and Thomas Lemieux, 2007; Wilbert Van der Klaauw, 2008; David Lee and Thomas Lemieux, 2010). As is often done in the empirical RD literature, we plot the raw means of the outcome variable (grouped by bins of two months) together with the kernel triangular estimates (using the same bandwidth as in the empirical model) and the 5\% confidence intervals around these estimates against the running variable. We plot each spouse's retirement probability after the 1993 reform as a function of own (left panel in Figure 2) and spousal birthday (right panel in Figure 2). To understand these graphs, it is important to keep in mind that spouses born to the left of the cut-off point (the vertical line at zero, which corresponds to being born on January 1934) are older while those born to the right are younger. After the reform, the husband's and the wife's retirement probability falls significantly, as expected. We find no significant indirect effects: the retirement probability of the husband (wife) is a smooth function of the birth date of the wife (husband)

Next, we run a "placebo" test in which we apply the same RD strategy but fictitiously assume that generations born in 1932 and later were affected by a reform implemented in1992 (Figure 3). ${ }^{9}$ The graphs show no significant drop in the retirement probability at the 1932 cutoff for either the husband or the wife. The placebo test thus validates our RD design: the effects we see in Figure 2 are not driven by a spurious combination of birth years and policy years.

\footnotetext{
${ }^{9}$ We drop from the estimation sample couples that answered the survey in 1994 and later years.
} 
Focusing on the legal retirement age, Figure 4 traces out the retirement probability of spouses as a function of own and spousal age. The jump in own retirement probability on reaching the legal retirement age 60 (the top panel of Figure 4) is over zero and under one (as it should be in a fuzzy RD) and very sizable for both the husband and the wife. We also find a small rise in the wife's retirement probability when the husband is aged 60 or over (the bottom right graph in Figure 4) but no visible effect of the wife's being aged 60 on the husband's retirement probability (the bottom left graph). Age differences between spouses may not be exogenous to household decisions. To control for this we use couple fixed effects in the econometric models.

We last check graphically that 60 is the only age cutoff that we should consider. We estimate (by means of a local polynomial method, applying a triangular kernel distribution and an optimal bandwidth of 48 months) the jump in the retirement probability of each spouse at:

- the legal retirement age of 60 (the top panel of Figure 4);

- the legal retirement age of 65 (the bottom panel in Figure A in the Appendix);

- age 55 (the top panel in Figure A in the Appendix), at which people typically enter sector-specific early-retirement schemes;

- the age of 55 years and 3 months (Figure B in the Appendix), starting at which the unemployed are exempt from making any active search effort and receive nonregressive unemployment benefits until retirement (Bommier, Magnac, Roger, 2003).

We saw that the retirement probability of each spouse jumps up for spouses aged 60 and above (Figure 4), with estimates of over 0.30 for the husband and over 0.25 for the wife (next Section). This difference reflects the fact that many married women have interrupted work 
histories with uninsured periods out of work, ${ }^{10}$ so that by the time they reach age 60 , they do not have sufficient social-security contributions to be able to retire with maximum pension benefits; they then opt to work some additional years to retire with the maximum pension. For the other age cut-offs considered (see the bullet list above), we find no significant increases in the retirement probabilities of either spouse, except for the age 65 cut-off at which there is a small jump into retirement for the wife (but not for the husband). This reflects the fact that married women have more often interrupted work history than married men, and thus, some of them retire at the legal retirement age of 65 , at which they can receive maximum pension benefits (see Section 4). As we focus on spillover effects and the husband is older than the wife in most couples (over two years older on average), we do not include in our model the spike in the wife's retirement probability when she is 65 (by then her husband will be on average 67 and over and will already be retired). The optimal bandwidth for the discontinuity in retirement at legal retirement age 60 is 48 months (Section 3).

\section{Estimation Results}

We estimate the effect of the 1993 retirement reform on own and spousal retirement by applying a sharp RD design, using both a local polynomial estimator and a linear regression model (Section 3) with the same (optimal) bandwidth. We also estimate the effect of spousal retirement (instrumented by the spouse's being aged 60, legal retirement age) on own retirement under a fuzzy RD design, by means of a local polynomial estimator and an instrumental variable model (Section 3). Next, we combine the laws for entitlement to maximum pension benefits (changed by the 1993 reform) with the legal retirement age. In all the models the standard errors are clustered at the couple level (or we include couple random

\footnotetext{
${ }^{10}$ They may have quit work, for example, to take care of children or their elderly parents (Kristian Bolin, Bjorn Lindgren and Petter Lundborg, 2008).
} 
or fixed effects). A number of robustness checks are carried out, which include varying the bandwidth, or dropping spouses born in January 1934.

\section{Sharp RD design: estimates of the direct effects of the 1993 policy reform}

The reform significantly reduced both spouses' retirement probability. The drop in the retirement probability is about 0.02 (or two percentage points) for the husband and 0.04 (or four percentage points) for the wife. When estimating a linear model with couple random effects, the estimates are slightly larger for the wife and double the size for the husband, for whom the retirement probability now drops by 0.04 . For the generations born shortly before the reform (from July to December 1933), mean retirement was 0.86 for the husband and 0.53 for the wife (about $26 \%$ of the wives are housewives). Therefore, the reform worked as expected inducing spouses to retire later. ${ }^{11}$ The two approaches, local polynomials using a triangular kernel estimator and linear regression model, lead to comparable results that are also robust to varying the bandwidth or dropping spouses born in January 1934 (Table1, Appendix).

\section{Sharp RD design: estimates of the indirect effects of the 1993 policy reform}

We now consider the indirect effects of the 1993 reform and estimate the wife's outcomes as a function of the husband's birthdate and vice-versa. The cut-off point is here whether the spouse was born in 1934. The estimates of the indirect effect of the reform on spousal retirement are negative but not significant statistically (Columns 1 and 2 of Table 2, Appendix). If the husband postpones retirement, than the wife will also have an incentive to do so, and vice-versa. This explains the negative coefficients on the cross-effects. The

\footnotetext{
${ }^{11}$ Earlier studies of the effect of the reform using an incremental differences-in-differences strategy also found very small reform effects on the individual retirement probability (Antoine Bozio, 2008).
} 
insignificance of these indirect effects is unsurprising given that the direct effects are quite small in size.

To check that we are not confounding the direct and indirect effect of the reform, we also reestimated similar RD models allowing for multiple discontinuities (Matias Cattaneo, Luke Keel, Rocio Titunik and Gonzalo Vazquez-Bare, 2015), specifying a discontinuity for the husband being born in January 1934 or later and an additional discontinuity for the wife being born in January 1934 or later. We therefore now explicitly allow spouses to be treated twice, once when they are hit by the reform (the direct effect) and then when their spouse is hit (the indirect effect). Under this set-up, we allow for the same bandwidth in both spouses' birth dates, and select couples in which both spouses were born within 48 months from January 1934. The estimated own effects are similar to those when estimating the two discontinuities separately and some of the cross retirement effects become now statistically significant (though only at the ten per cent statistical significance level), suggesting that spousal retirement affects own retirement by one to four percentage points (Table 1).

\section{Sharp RD design: a placebo of the 1993 policy reform}

To check the validity of our RD analysis, we replicate (for the sample years between 1990 and 1993) a similar set up for spouses born in 1932 and later years (up to 1933), assuming fictitiously that a similar reform appeared in 1992. Figure 3 shows no direct or indirect effect of this fictitious reform on spouses' outcomes (for the sake of brevity we do not show these estimation results, which are available from the author).

\section{Fuzzy RD design (or IV): instrumenting spousal retirement with legal retirement age}

We further investigate spouses' retirement strategies by exploiting the large discontinuity in retirement at the legal retirement age of 60 (see top panel of Figure 4). Regarding 
anticipations, although age and retirement can be anticipated, the legal retirement age constraints are binding so that spouses cannot anticipate retirement. The older spouse could postpone retirement but their pension income would not increase. The age difference in the average couple is over two years and retirement schemes are individually designed with no spousal benefits but legal retirement ages. French administrative surveys of retirees reveal that $78 \%$ of retirees say that family considerations had no impact at all on their decision to retire, while $49 \%$ say that having reached the age at which they can retire with maximum pension benefits was a very important reason to retire (multiple answers were possible: see Appendix Table B). The age difference between spouses may not be exogenous to spousal decision making, an issue which has been neglected in most of the literature on spouses' retirement to date. We pick this up by estimating a model including couple fixed effects (Table 2).

We first note that the first-stage estimates are very significant, and indicate a large jump in own retirement probability for each spouse at age 60 and above. In particular, the husband's retirement probability increases by 0.32 in the local polynomial estimator and 0.34 in the linear regression model; the analogous figures for the wife are 0.25 and 0.27 respectively. These smaller estimates for the wife reflect that married women tend to have more interrupted work careers and thus need to work to a later age to be able to retire with maximum pension benefits. We now also find a significant and positive effect of own retirement on spousal retirement: the husband's retirement probability rises by 0.05 to 0.06 ( 5 to 6 percentage points) when the wife retires, with analogous figures for the wife of 0.02 to 0.03 ( 2 to 3 percentage points) - although the latter estimate is statistically insignificant in the local polynomial regressions.

Next, we estimated linear regression models in which each spouses' retirement probability varies as a function of whether either spouse is aged 60 or more, thus allowing for multiple 
cut-offs. The bandwidth is set accordingly and includes couples in which both spouses are aged within 48 months from age 60 . The estimates show that the jump in own retirement at own age 60 is robust to controlling for the spouse's being (also) aged 60, but many of the cross-effects are not significant (although they are all positive). In particular, controlling for the own jump into retirement at age 60 in addition to the discontinuity in own retirement when the spouse is aged 60, makes the size of the latter estimate smaller (Table $\mathrm{C}$ in the Appendix).

\section{Intensive margin of labor supply: market-hour outcomes}

Retirement is an absorbing state in France, with very few people continuing to work past retirement, at least in the period we consider: only $1.3 \%$ of the husbands and $0.6 \%$ of the wives report positive hours after having retired from work. ${ }^{12}$ Therefore, it is difficult to pin down the effect of retirement on own hours. We also find no indirect effect of the 1993 reform on the spouse's hours of work (if the husband is affected by the reform, the wife hours of work do not vary significantly, and vice-versa), and small effects of spousal retirement (instrumented with the spouse's being aged 60 and above) on own hours of work. The hours of work of the husband drop by about 1.8 hours per week when the wife retires while the hours of work of the wife drop by about 1.3 hours per week when the husband retires, but these estimates are statistically significant only when controlling for couple's fixed effects.

\section{Interacting legal retirement age and maximum pension benefit laws}

As we have seen, since the 1993 reform, workers born in 1934 and later years had to work more quarters to be able to retire with maximum pension benefits, which led both spouses to postpone retirement. We have also established that each spouse's retirement probability

\footnotetext{
${ }^{12}$ Precisely, 572 husbands report positive hours out of the 43679 that have retired from work in our sample of 74942 husbands aged within 48 months from age 60 (the estimation sample in Column 3 of Table 4) and 159 wives report positive hours out of the 25357 that have retired from work in our sample of 71612 wives aged within 48 months from age 60 (the estimation sample in Column 2 of Table 4).
} 
increases dramatically at the legal retirement age of 60 . We now construct a measure of the "potential" social security contribution period of each spouse, based on the education level, ${ }^{13}$ (assuming that individuals entered the labor market as soon as they completed education), the year of birth and the laws on compulsory schooling years. ${ }^{14}$ Next, we calculate for each spouse the "optimal" social security contributions required for them to be able to retire with maximum pension benefits, which is a function of their birth year since the 1993 reform (abstracting from any variation due to the sector of employment and taking the private sector as the reference here). ${ }^{15}$ Subtracting the potential social security contributions (measured in months at the date of the survey) from the optimal contributions (required for receiving maximum pension benefits), we obtain a measure of the "potential" 16 distance in months from the moment at which each spouse is able to retire with maximum pension benefits. The treatment is then defined as having enough social security contributions to be able to retire with maximum pension benefits. However, we need to account also for the existence of legal retirement ages, and thus, we interact the social security treatment dummy (equal to one for spouses that have already reached the month at which they can potentially retire with maximum pension benefits, and to zero otherwise) with the dummy for being aged 60 and above. The running variable is obtained by interacting the distance in months from being aged 60 with the distance in months from the optimal contributions.

We then estimate Fuzzy RD models of the effect of spousal retirement (instrumented with the spouses' being aged at least 60 and having attained the optimal contribution record) on own

\footnotetext{
${ }^{13}$ School was compulsory until age 14 until 1959, when a reform extended compulsory schooling to age 16 for children that were at least six years old as from January 1959.

${ }^{14}$ Until 2004, women were credited some additional social security contributions (one extra year of pension rights) for each child, conditional on being employed around the time the child was born. This was on top of the pension rights accrued during the maternity leave period. However, the LFS only ask about children still leaving at home but by the time parents retire children have often left the parental home.

${ }^{15}$ Not only spouses may change sector of employment over their life course, but also the sector of employment is chosen, and thus not exogenous. Therefore, we do not make any attempt to control here for the spouses' sector of employment.

${ }^{16}$ We use the term potential to emphasize that we do not use the actual social security contributions, which are not observed and also likely endogenous here.
} 
retirement. To allow for the fact that spouses are "treated" twice because of the own and the spousal treatment, we also estimate a models of each spouse's retirement as a function of both spouses' being aged 60 and having attained the optimal contribution record. The results of estimation corroborate our conclusions of significant cross-effects of own retirement on spousal retirement (Table 3). In particular, the estimates obtained are very similar to those obtained considering only the effect of the 1993 reform on both spouses' retirement (Table 1) or using the legal retirement age of 60 to instrument spousal retirement (Table 2). Each spouse's retirement probability increases by 0.01 to 0.03 (one to three percentage points), when the other spouse is treated - but the jump in own retirement is about 0.30 to 0.40 upon own treatment.

\section{Conclusions}

Population ageing and increasing budgetary pressure have led most OECD countries to introduce policies to extend individual working lives. Over two-thirds of individuals of retirement age live as couples and it is therefore of great importance for policy purposes to understand the retirement strategies of married workers. Our work is novel in a number of respects. The employment rates of older married women in France are very high (above those of their American counterparts), which makes it possible to estimate the effects of a retirement-policy reform on both spouses. The earlier literature considers the employment decisions of dual-earners in North-American, British and North-European, countries, in which private-pension schemes and spousal pension benefits are widespread. Like other Central European or Mediterranean countries, around 80 per cent of French retirees receive only first pillar (public) pension benefits, which are individually designed and there are no spousal pension benefits in France. Health insurance is also universal and public. 
We here exploit a pioneering 1993 retirement reform, providing incentives for workers to postpone retirement, to identify the direct and indirect effects of the reform on spouses' retirement outcomes. We also make use of the discontinuity in retirement at the legal retirement age to gain additional insights into spouses' joint retirement patterns. Last, we combine the two treatments and interact the social security law on maximum pension benefits (reformed in 1993) with the legal retirement age. We estimate both local polynomial models using triangular kernel estimators and linear regression models with (linear) polynomials in the forcing variable (and their interaction with the cut-off). These models are estimated with (rotating) panel data on over 50000 French couples, and we control for individual unobserved heterogeneity (or cluster the standard errors at the couple's level).

We conclude that due to the 1993 policy reform, own probability of retirement fell immediately by about 2 percentage points for the husband and about 4 percentage points for the wife. In addition, own retirement probability drops by one to four percentage points when the spouse is impacted. We also exploit the discontinuity in own retirement probability at age 60 (which is the legal retirement age for most workers in France) and apply a fuzzy regression discontinuity approach (which can also be seen as an instrumental-variable approach). We also find that the husband's retirement probability increases by 2 to 6 percentage points upon the wife's retirement (instrumented with legal retirement age) and vice-versa for the wife. In contrast, the estimated jump in own retirement probability at age 60 is 32 to 35 percentage points for the husband and 25 to 27 percentage points for the wife. Combing the social security laws on eligibility to maximum pension benefits (changed by the 1993 reform) with the legal retirement age to instrument each spouse's retirement, we obtain similar estimates: spousal retirement increases own retirement by about 1 to 3 percentage points but the jump in own retirement at own treatment is equal to over 30 percentage points for both spouses. 
Because many OECD countries have increased legal retirement ages and many individuals of retirement age live as couples, this study is globally relevant. We conclude that policies impacting one spouse's retirement decision also affect the other, in line with the argument that spouses plan their retirement together. Although we are fully aware that each of them has some limitations, the three alternative empirical RD approaches taken provide similar-size estimates of the IIT impact of retirement law on spouses' retirement strategies. The own effect always dominate the indirect effect on the spouse, as plausible, since spouses are tight to retirement laws themselves and cannot flexibly decide when to retire. In particular, in the case of France retirement system, which resembles that of many other European countries, while individuals can opt to retire with less than maximum pension benefits, they cannot choose to retire before legal retirement age. The evidence gathered here suggests that jointretirement (as captured by the spillover or indirect effect of the retirement law on the spouse) is in the range of 1 to 6 per cent, with our preferred estimate being about 4 per cent.

\section{References}

An, Mark Y., Bent Jesper Christensen and Nabanita Datta Gupta (2004), "Mutivariate Mixed Proportional Hazard Modelling of the Joint Retirement of Married Couples", Journal of Applied Econometrics, 19, pp. 687-704.

Angrist, Joshua D. and Jorn-Steffen Pischke (2009) "Mostly Harmless Econometrics: An Empiricist's Companion”, Princeton University Press.

Aubert, Patrick, Nadine Barthelemy and Samia Benallah (2012), "Le départ à la retraite : motivations et connaissance des droits", DREES Recherches Etudes Evaluation et Statistiques, 34, 1-44.

Baker, Michael (2002). The Retirement Behavior of Married Couples: Evidence from the Spouse's Allowance, Journal of Human Resources, 37(1), 1-34.

Banks, James, Richard Blundell, and Maria Casanova Rivas (2010), "The dynamics of retirement behaviour in couples: reduced form evidence from England and the US," mimeo, 2010.

Battistin, Erich, Agar Brugiavini, Enrico Rettore and Guglielmo Weber (2009), "The Retirement Consumption Puzzle: Evidence from a Regression Discontinuity Approach" American Economic Review, 99(5), 2209-2226. 
Behagel, Luc, Didier Blanchet, and Muriel Roger (2014), "Retirement, Early-Retirement and Disability: Explaining the Labor Force Participation after 55 in France", NBER, Working Paper No. 20030.

Blau, Francine, D. and Lawrence, M. Kahn (2013), "Female Labor Supply: Why is the US falling Behind", American Economic Review, 103(3), 251-56.

Blau David M. (1998), Labor Force Dynamics of Older Married Couples, Journal of Labor Economics, 16(3), 595-629.

Bloemen, Hans and Stancanelli, Elena (2013), "Toyboys or Supergirls? An analysis of partners' employment outcomes when she outearns him", Review of the Economics of the Household, August, 1-30.

Bolin, Kristian, Bjorn Lindgren and Petter Lundborg (2008) "Your next of kin or your own career? Caring and working among the 50+ of Europe." Journal of Health Economics 27(3), $718-738$.

Bommier, Antoine, Thierry Magnac and Muriel Roger (2003), "Le marché du travail à l'approche de la retraite : évolutions en France entre 1982 et 1999", Revue Française d'Economie, XVIII(1), 23-82.

Bovenberg, Lans (2011), "Pension reform in the Netherlands from an international perspective", mimeo.

Bozio Antoine, (2008), "Impact evaluation of the 1993 French pension reform on retirement age" in Pensions : An International Journal, 13 (4), 207-212.

Calonico, Sebastian, Matias D. Cattaneo and Rocio Titiunik (2014), "Robust Non-Parametric Confidence Intervals for Regression Discontinuity Designs", Econometrica, 82 (6), 2295 2326.

Casanova, Maria, "Happy Together: a structural model of couples' joint retirement choices," mimeo, 2010.

Cattaneo, Matias, D., Luke Keel, Rocio Titunik and Gonzalo Vazquez-Bare (2015), "Identification in Regression Discontinuity Designs with Multiple Cutoffs", mimeo.

Chiappori, Pierre-André, Sonia Oreffice and Climent Quintana-Domeque (2012), "Fatter attraction: anthropometric and socioeconomic matching on the marriage market", Journal of Political Economy, 120(4), 659-695.

Coile, Courtney C. (2004), "Retirement incentives and couples' retirement decisions," Topics in Economic Analysis \& Policy, 4(1), 1-28.

Cribb, Jonathan, Carl Emmerson and Gemma Tetlow (2014), "How does increasing the early retirement age for women affect the labour supply of (women and their) husbands?, IFS. 
Gerard, Francois and Lena Nekby (2012), "Spousal Retirement: A Reform Based Approach to Identifying Spillover Effects", mimeo.

Gilleskie, Donna B. and David M. Blau (2006), "Health insurance and retirement of married couples," Journal of Applied Econometrics, 21(7), 935-953.

Gruber, Jonathan and David Wise (2005), "Social Security Programs and Retirement around the World: Fiscal Implications, Introduction and Summary,"NBER Working Papers 11290, National Bureau of Economic Research, Inc.

Gustman, Alan and Thomas Steinmeier (2009), Integrating Retirement Models, NBER Working Paper 15607.

Gustman, Alan and Thomas Steinmeier (2000), Retirement in Dual-Career Families: A Structural Model, Journal of Labor Economics, 18, 503-545.

Hairault, Jean-Olivier , Francois Langot and Thepthida Sopraseuth (2010), "Distance to Retirement and Older Workers' Employment: The Case for Delaying the Retirement Age", Journal of the European Economic Association, 8(5), 1034-1076.

Hahn, Jinyong, Petra Todd and Wilbert Van der Klaauw (2001), Regression-Discontinuity Design, Econometrica, 69 (1), 201-209.

Honoré, Bo and Aureo de Paula ( 2014), "Joint Retirement in Europe”, NETSPAR Discussion Paper, No. 10/2014-052.

Hurd, Michael (1990), The Joint Retirement Decision of Husbands and Wives, in: Issues in the Economics of Aging, David Wise (ed.), NBER, pp. 231-258.

Imbens, Guido and Thomas Lemieux (2007), Regression Discontinuity Design: a Guide to Practice, Journal of Econometrics, 142, 615-635.

Kapur, Kanika and Jeannette Rogowski (2007), 'The role of health insurance in joint retirement among married couples', Industrial and Labor Relations Review, 60 (3), 397-407.

van der Klaauw, Wilbert (2008), "Regression Discontinuity Analysis: a Survey of Recent Developments in Economics”, Labour, 22(2), 219-245.

van der Klaauw, Wilbert and Kenneth Wolpin (2008), "Social Security and the Retirement and Savings Behavior of Low Income Households", Journal of Econometrics, 145 (1-2), 21 42.

Lahey, Joanna (2008), “Age, Women, and Hiring: An Experimental Study”, Journal of Human Resources, 43(1), 30-56.

Lalive, Rafael and Stefan Staubli (2014), “How Does Raising Women's Full Retirement Age Affect Labor Supply, Income, and Mortality? Evidence from Switzerland”, August, 2014, mimeo. 
Lee, David S. (2008), "Randomized experiments from non-random selection in the U.S. House Elections", Journal of Econometrics, 142, 675-697.

Lee, David S. and Thomas Lemieux (2010), Regression Discontinuity Designs in Economics, Journal of Economic Literature, 48(2), 281-355.

Michaud, Pierre-Carl and Frederic Vermeulen (2011), “A collective labor supply model with complementarities in leisure: identification and estimation by means of panel data", Labour Economics, 18, 159-167.

McCrary, Justin (2008), "Manipulation of the Running Variable in the Regression Discontinuity Design: A Density Test," Journal of Econometrics, 142, 698-714.

Nichols, Austin (2014), "Stata Module for Regression Discontinuity Estimation", Stata journal, Boston College.

OECD (2014), Estimates of effective retirement age, based on the results of national labour force surveys, the European Union Labour Force, OECD, online statistics.

Pollak, Robert A. (2013), 'Labor Supply and Claiming Social Security Benefits: A Couples' Perspective", unpublished, mimeo.

Sédillot, B. and E. Walraet, (2002), "La cessation d'activité au sein des couples: y a-t-il interdépendance des choix?", Economie et Statistique, 357-358 
Figure 1. Labor-Force Participation Rates of Men and Women Aged 45 to 54.

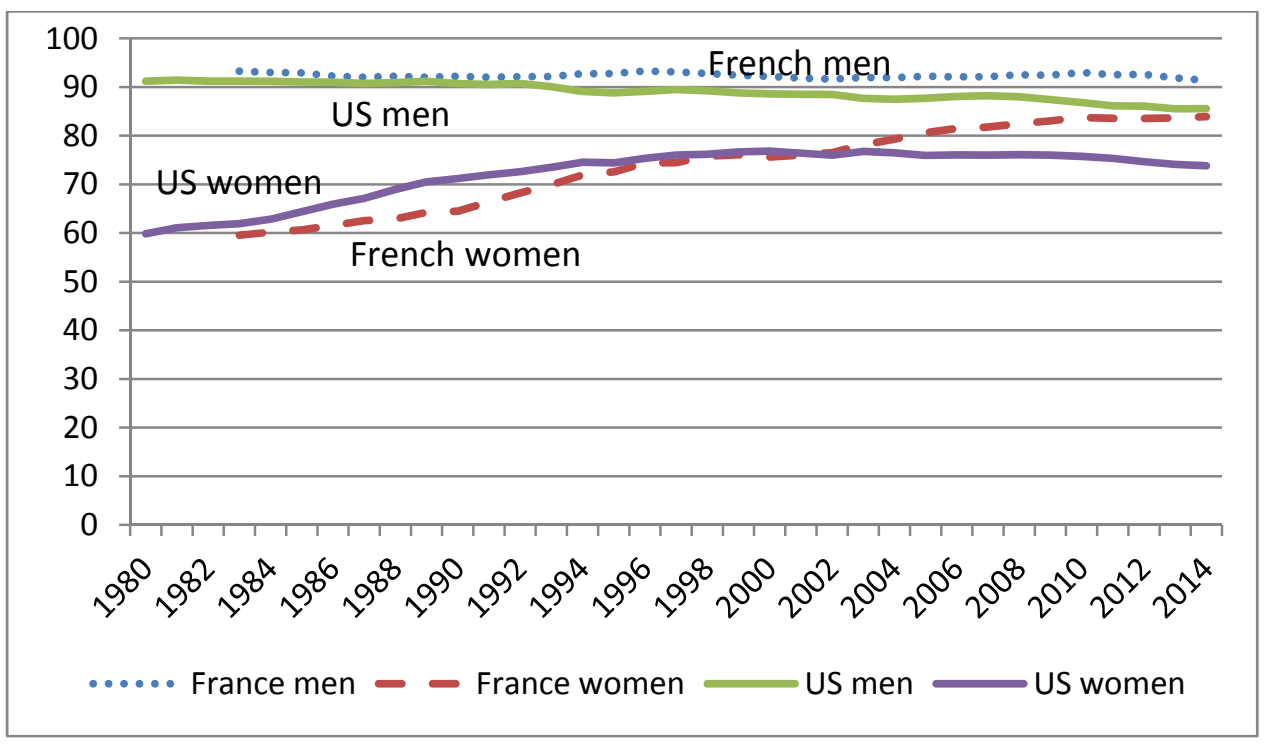

Source: OECD Statistics Online. 
Figure 2. Husband's and Wife's Retirement Probability after the 1993 Reform
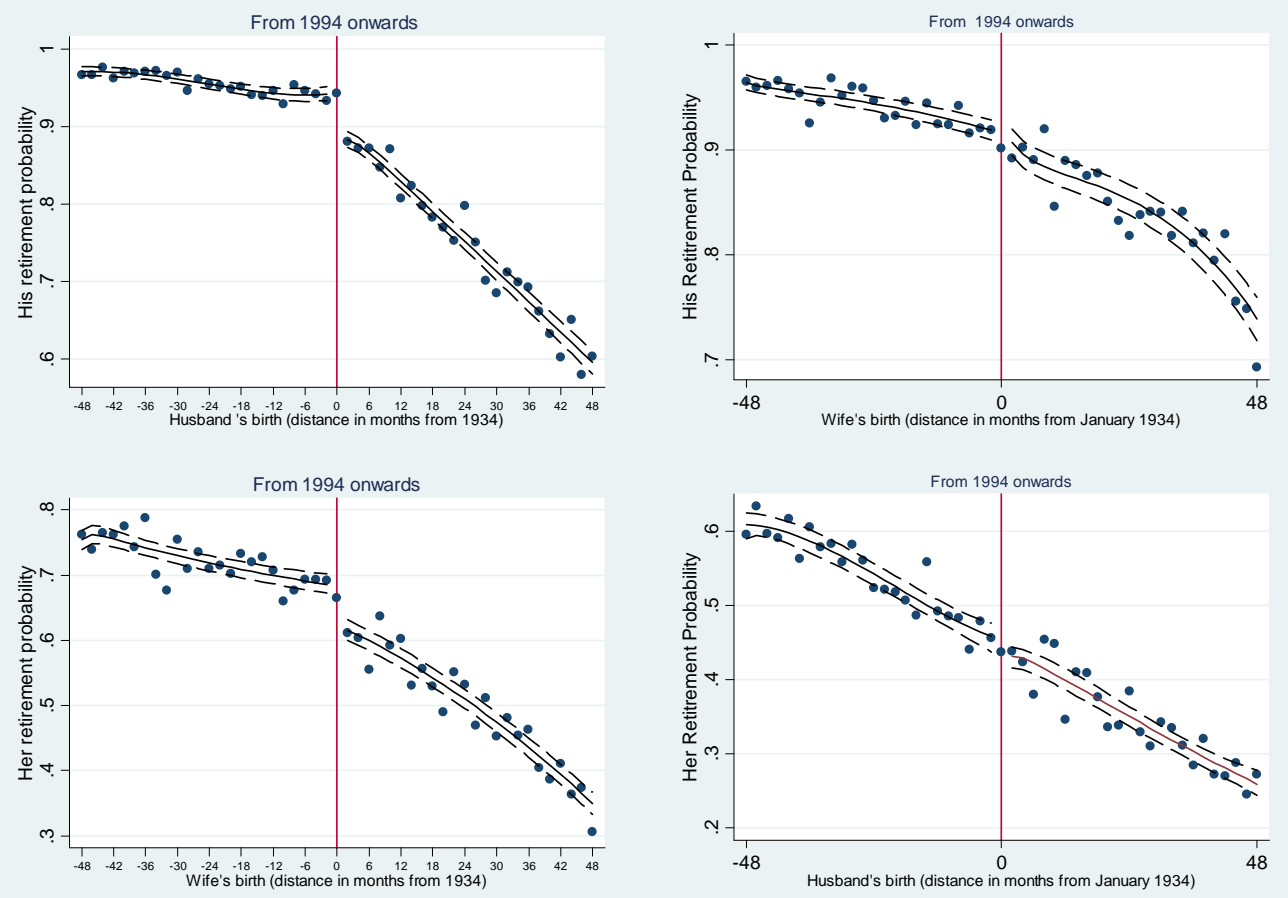

Note: The graphs show the retirement probability of the husband (top panel) and the wife (bottom panel) by own month of birth (left panel) and by spouse's month of birth (right panel), respectively, after the 1993 reform. The birth month of "zero" corresponds to January 1934: individuals born in 1934 and later were hit by the retirement reform in 1994. The observations are grouped by bins of two months. The dots are the raw means of the outcome variable (the retirement probability) which is plotted against the running variable (distance in months from being born in January 1934 or spousal distance in months from being born in January 1934, respectively). The solid line is non-parametrically fitted using a triangular kernel with a bandwidth of 48 months. The dotted lines are the 5 percent confidence bounds around the kernel estimates. 
Figure 3. Placebo: Husband's and Wife's Retirement Probability after the "1992 fictitious reform"
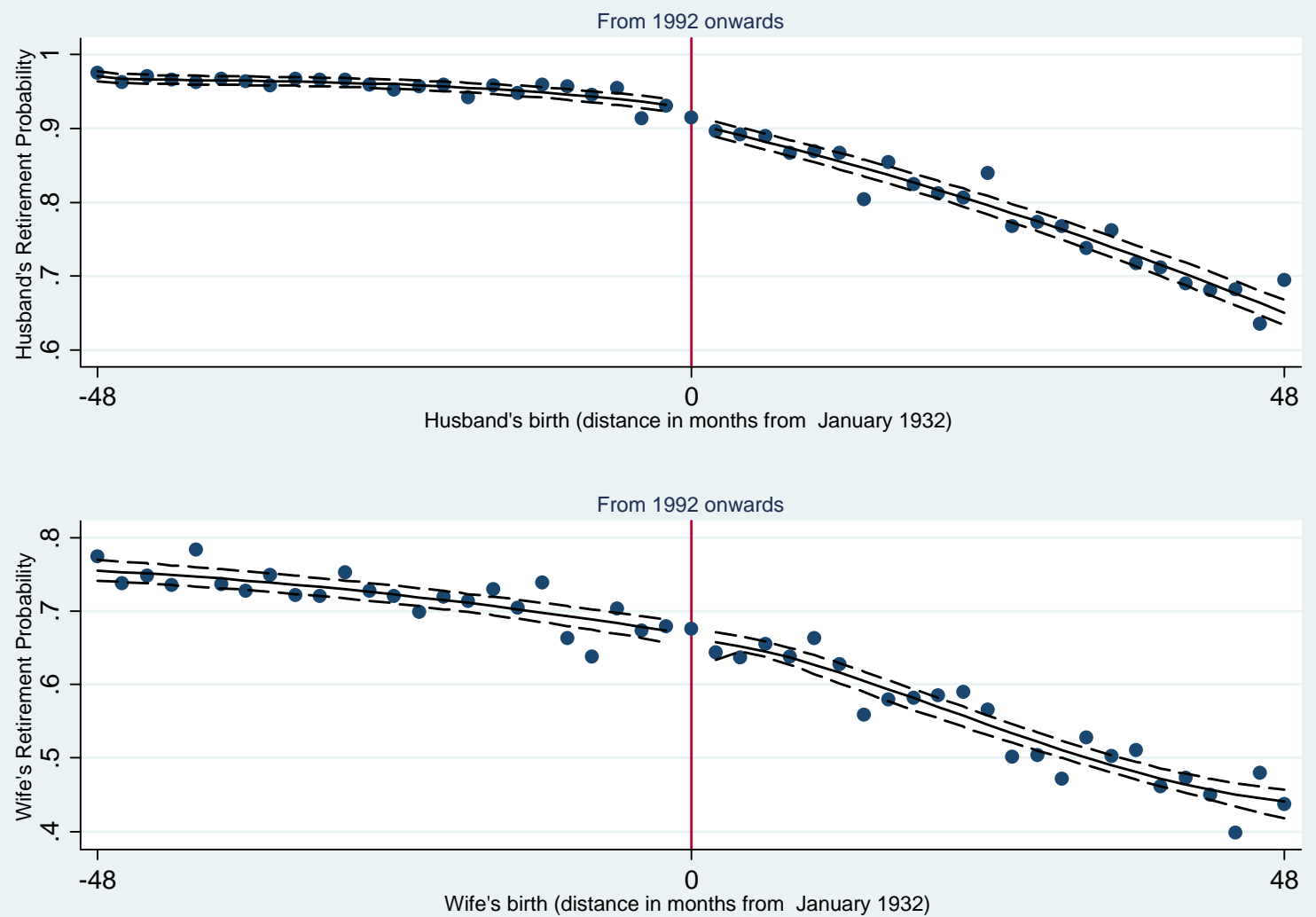

Note: The graphs show the retirement probability of the husband (top panel) and the wife (bottom panel) by own month of birth before and after 1992. There was no reform in 1992; these graphs are a counterfactual of the 1993 reform. The birth month of "zero" corresponds to January 1932. The observations are grouped by bins of two months. The dots are the raw means of the outcome variable (the retirement probability) which is plotted against the running variable (distance in months from being born in January 1932). The solid line is nonparametrically fitted using a triangular kernel with a bandwidth of 48 months. The dotted lines are the 5 percent confidence bounds around the kernel estimates. 
Figure 4. Husband's and Wife's Own and Cross Retirement Probability at age 60
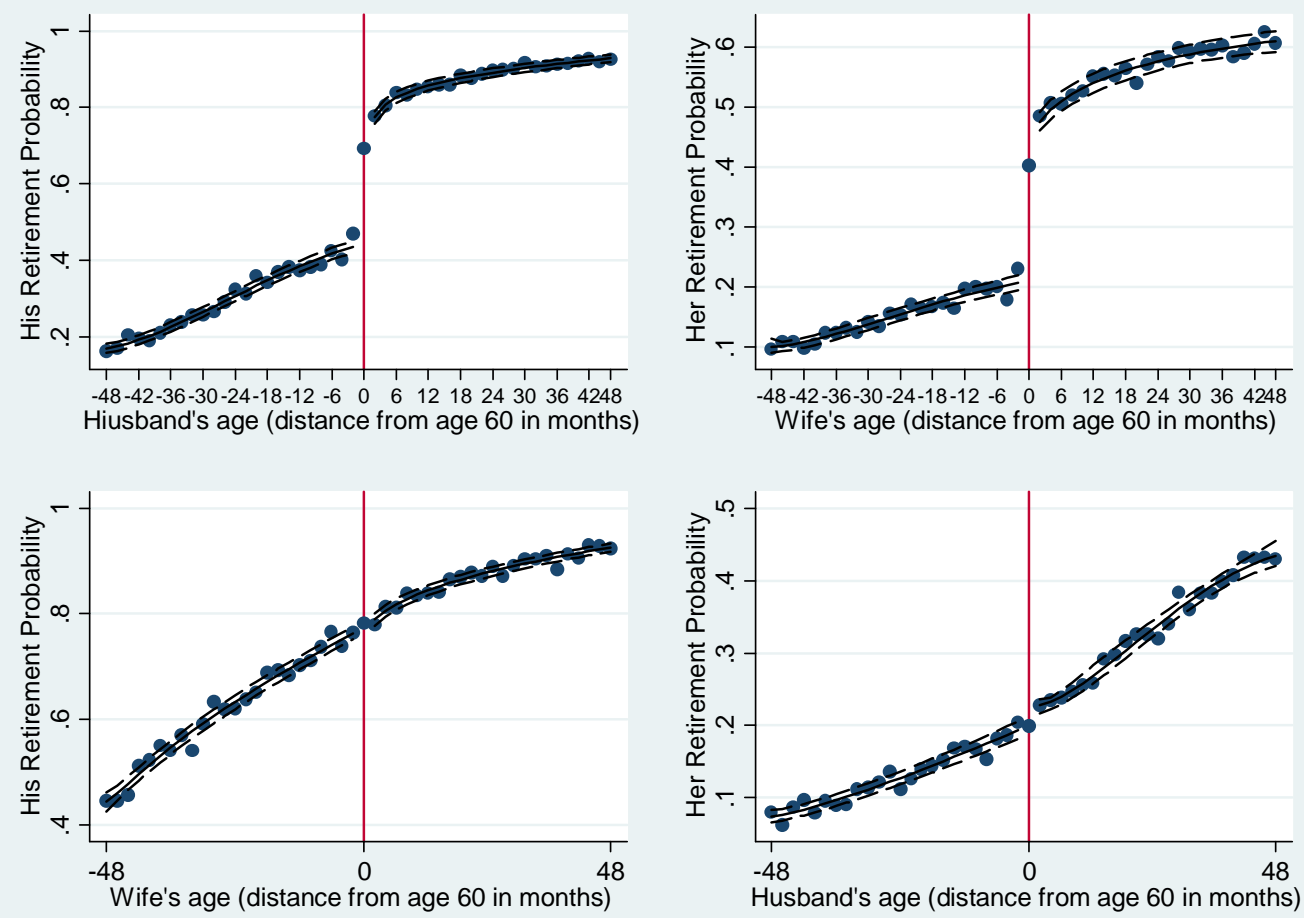

Note: The graphs show the retirement probability of the husband (top panel) and the wife (bottom panel) by own and spouse's age. The age of "zero" corresponds to being aged 60, which is the legal retirement age for most workers in France (see the discussion in the text). The observations are grouped by bins of two months. The dots are the raw means of the outcome variable (the retirement probability) which is plotted against the running variable (distance in months from being aged 60 when interviewed). Retirement status is measured at the interview date. The solid line is non-parametrically fitted using a triangular kernel with a bandwidth of 48 months. The dotted lines are the 5 percent confidence bounds around the kernel estimates. 
Table 1. Estimation results of the direct and indirect effect of the 1993 reform for the spouses.

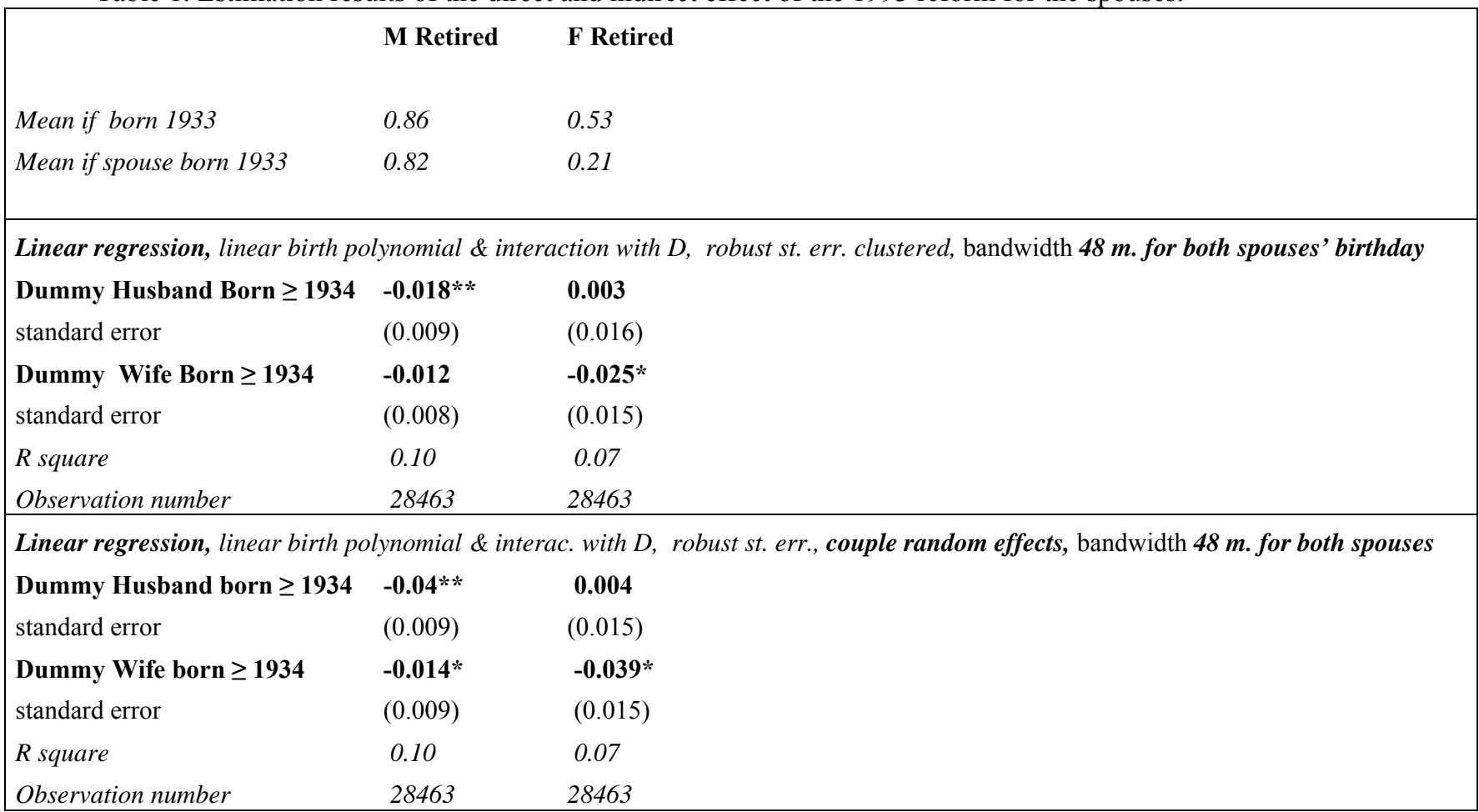

Note: The linear regression model includes linear polynomials in the distance from birth in 1934 for each spouse and interaction of the dummy for being born in 1934 and later years with this polynomial for each spouse. The standard errors are robust and are also clustered at the couple's level. Standard errors appear in parentheses. In the table, ${ }^{* *}$ indicates statistical significance at the $5 \%$ level and * indicates statistical significance at the $10 \%$ level. 
Table 2. Estimation results of the indirect effect of spouse's retirement on own retirement (2SLS)

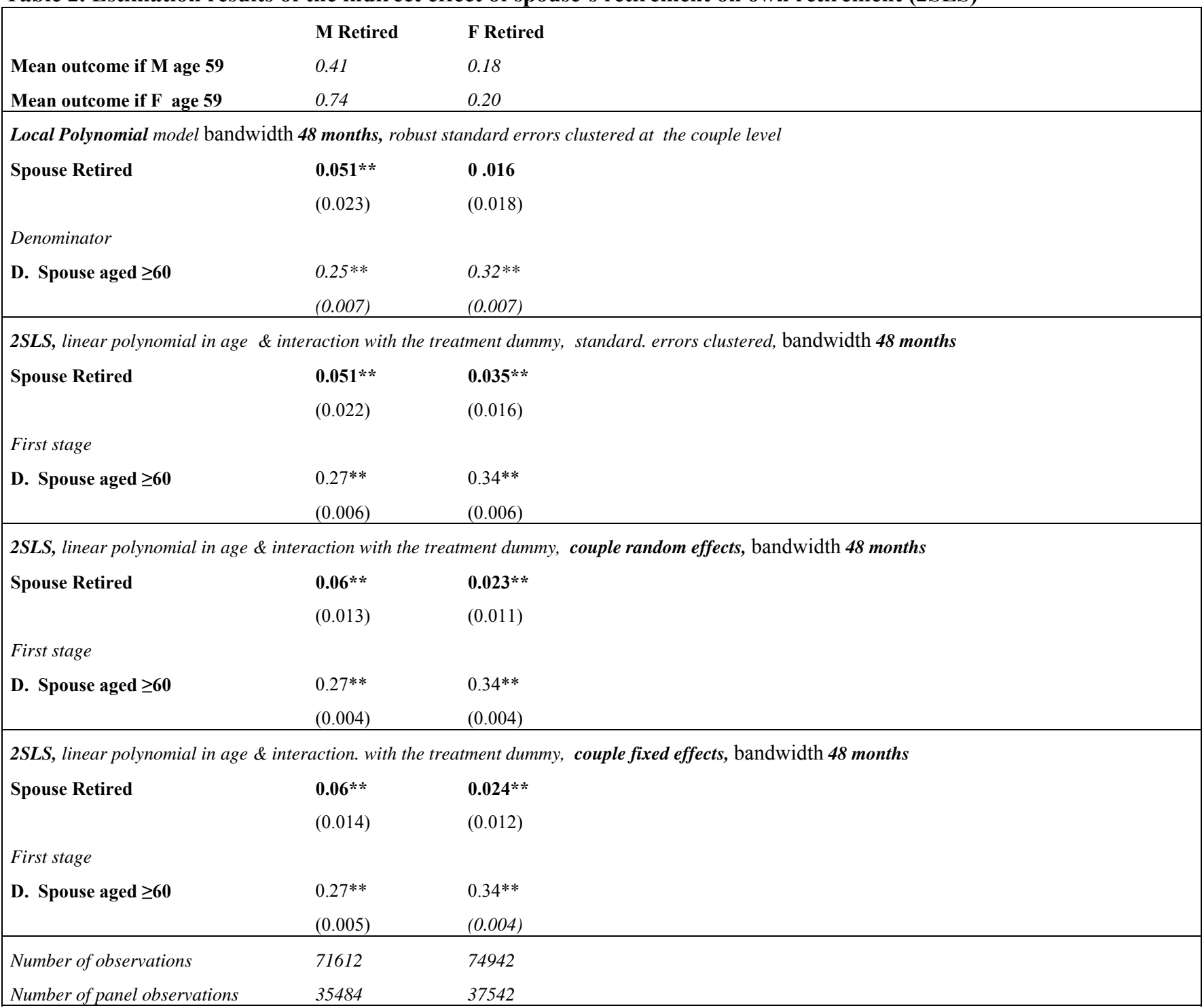

Note: The local linear polynomials are estimated using a non-parametric triangular kernel. The standard errors are adjusted and clustered at the couple's level. The Two Stages Least Square (2SLS) model include linear polynomials in the age (distance in months from age 60 at the date of the interview) and a linear interaction of the dummy for being aged 60 and above with this polynomial in the both the outcome and the first stage equations. The standard errors are robust and are also clustered at the couple level. Standard errors are given in brackets. In the table, $* *$ indicates statistical significance at the 5\% level and * indicates statistical significance at the $10 \%$ level. Here the bandwidth is set with respect to the spouse whose retirement is been instrumented with $\mathrm{s} /$ he being aged 60 and above. 
Table 3. Estimation results of the direct and indirect effect of spouse's retirement on own retirement: combining the legal retirement age and the social security contributions for "maximum" benefits

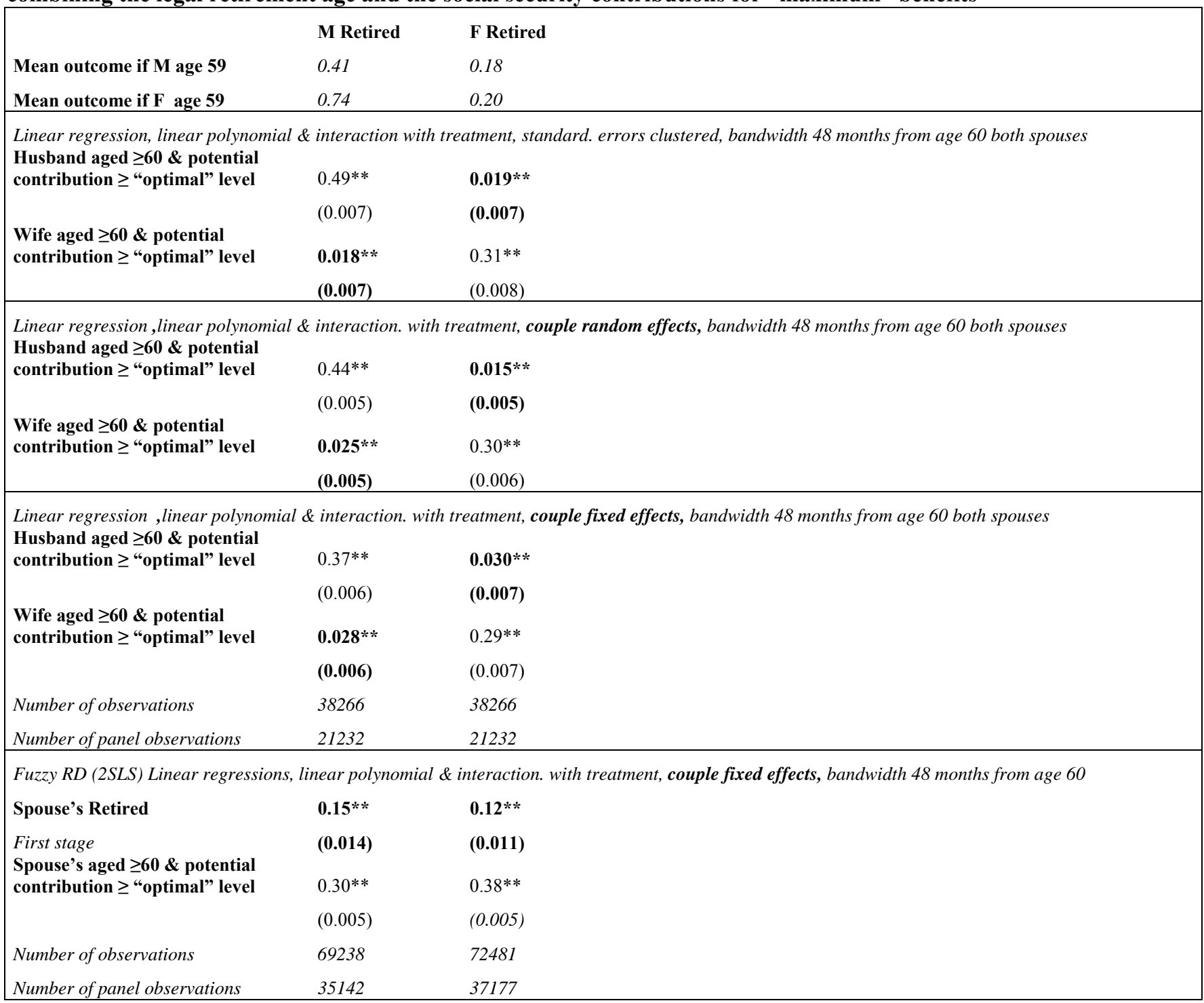

Note: The models include linear polynomials in the age (distance in months from age 60 at the date of the interview) interacted with the distance in months from the optimal social security contribution record and a linear interaction of this polynomial with the treatment dummy (which is equal to the interaction of the dummy for being aged 60 and above with the dummy for having contributed at least enough social security contributions to be able to retire with 'maximum' pension benefits. Standard errors are given in brackets. In the table, ** indicates statistical significance at the 5\% level and * indicates statistical significance at the $10 \%$ level. For the Fuzzy RD (which is equivalent to 2SLS) the bandwidth is set with respect to the age of the spouse whose retirement is been instrumented while in the other models the bandwidth is set with respect to both spouses' age. 


\section{Appendix}

Table A. Estimation results of the direct effect of the 1993 reform for the spouses (own effects)

\begin{tabular}{lll|}
\hline \multicolumn{1}{|c}{ Outcome: } & M Retired & F Retired \\
Mean if born in 1933 & 0.86 & 0.53 \\
(st dev. from the mean) & $(0.35)$ & $(0.50)$ \\
\hline Local Polynomial model bandwidth $\mathbf{4 8}$ months, & robust standard errors clustered at the couple level \\
Dummy for born $\geq \mathbf{1 9 3 4}$ & $\mathbf{- 0 . 0 1 9 7 * *}$ & $\mathbf{- 0 . 0 3 9 * *}$ \\
(standard error) & $(0.007)$ & $(0.013)$ \\
Observation number & 51350 & 48284 \\
\hline
\end{tabular}

Local Polynomial model bandwidth 24 months, standard errors clustered at the couple level

Dummy for born $\geq 1934 \quad-0.0169^{* *} \quad-0.036 * *$

$(0.009) \quad(0.0188)$

Local Polynomial model bandwidth 96 months, standard errors clustered at the couple level

Dummy for born $\geq 1934 \quad-\mathbf{0 . 0 1 4 5 * *} \quad-\mathbf{0 . 0 4 3 6 * *}$

$(0.005) \quad(0.009)$

Linear regression, linear birth polynomial \& interaction with $D$, standard errors clustered, bandwidth $\mathbf{4 8} \mathbf{m}$.

Dummy for born $\geq 1934 \quad-\mathbf{0 . 0 2 0} * * \quad-\mathbf{0 . 0 3 2 9} * *$

$(0.007) \quad(0.012)$

R square $\quad 0.117 \quad 0.065$

Observation number $\quad 51350 \quad 48284$

Linear regression, linear birth polynomial \& interaction with $D$, couple random effects, bandwidth $48 \mathrm{~m}$.

Dummy for born $\geq 1934 \quad-0.0449 * * \quad-0.049 * *$

$(0.007) \quad(0.0117)$

Overall R-squared $\quad 0.116 \quad 0.065$

Number of observations $\quad 51350 \quad 48284$

Number of panel observations $22907 \quad 21452$

The local linear polynomials are estimated using a non-parametric triangular kernel. The standard errors are adjusted and clustered at the couple level. The linear regression model includes linear polynomials in the distance from birth in 1934 and interaction of the dummy for being born in 1934 and later years with this polynomial. The standard errors in parentheses are robust and are also clustered at the couple level. In the table, ** indicates statistical significance at the $5 \%$ level and * at the $10 \%$ level. 
Table B. Estimation results of the indirect effect of the 1993 reform for the spouses (cross-effects)

\begin{tabular}{|c|c|c|}
\hline & M Retired & F Retired \\
\hline Mean if born 1933 & 0.86 & 0.53 \\
\hline Mean if spouse born 1933 & 0.82 & 0.21 \\
\hline \multicolumn{3}{|c|}{ Local Polynomial model bandwidth $\mathbf{4 8}$ months, robust standard errors clustered at the couple level } \\
\hline D. Spouse born $\geq 1934$ & -0.0010 & -0.0048 \\
\hline standard error & $(0.008)$ & $(0.014)$ \\
\hline Observation number & 48284 & 51350 \\
\hline \multicolumn{3}{|c|}{ Local Polynomial model bandwidth $\mathbf{2 4}$ months, robust standard errors clustered at the couple level } \\
\hline \multirow[t]{2}{*}{ D. Spouse born $\geq 1934$} & -0.014 & -0.007 \\
\hline & $(0.011)$ & $(0.0198)$ \\
\hline \multicolumn{3}{|c|}{ Local Polynomial model bandwidth 96 months, robust standard errors clustered at the couple level } \\
\hline \multirow[t]{2}{*}{ D. Spouse born $\geq 1934$} & 0.009 & -0.0118 \\
\hline & $(0.006)$ & $(0.0098)$ \\
\hline \multicolumn{3}{|c|}{ Linear regression, linear birth polynomial \& interaction with D, robust st. err. clustered, bandwidth $\mathbf{4 8} \mathbf{m}$. } \\
\hline \multirow[t]{2}{*}{ D. Spouse born $\geq 1934$} & -0.004 & -0.008 \\
\hline & $(0.007)$ & $(0.012)$ \\
\hline$R$ square & 0.036 & 0.047 \\
\hline Observation number & 48284 & 51350 \\
\hline \multicolumn{3}{|c|}{ Linear regression, linear birth polynomial \& interac. with D, robust st. err., couple random effects, bandwidth 48 m. } \\
\hline \multirow[t]{2}{*}{ D. Spouse born $\geq 1934$} & -0.008 & -0.015 \\
\hline & $(0.007)$ & $(0.012)$ \\
\hline Overall R-squared & 0.036 & 0.047 \\
\hline Number of observations & 48284 & 51350 \\
\hline Number of panel observations & 21452 & 22907 \\
\hline
\end{tabular}

Note: The local linear polynomials are estimated using a non-parametric triangular kernel. The standard errors are adjusted and clustered at the couple level. The linear regression model includes linear polynomials in the distance from birth in 1934 and interaction of the dummy for being born in 1934 and later years with this polynomial. The standard errors are robust and are also clustered at the couple's level. Standard errors appear in parentheses. In the table, ${ }^{* *}$ indicates statistical significance at the $5 \%$ level and $*$ indicates statistical significance at the $10 \%$ level. 
Table C. Estimation results of the direct and indirect effect of spouse's retirement on own retirement (linear regression models allowing for own and spouse's legal retirement age)

\begin{tabular}{|c|c|c|}
\hline \multicolumn{3}{|c|}{ All couples } \\
\hline \multirow{3}{*}{$\begin{array}{l}\text { Mean outcome if } M \text { age } 59 \\
\text { Mean outcome if } F \text { age } 59\end{array}$} & M Retired & F Retired \\
\hline & 0.41 & 0.18 \\
\hline & 0.74 & 0.20 \\
\hline \multicolumn{3}{|c|}{ Linear regression, linear polynomial in age \& interaction with the treatment dummy standard errors clustered, bandwidth $\mathbf{4 8} \mathbf{~ m}$. } \\
\hline \multirow[t]{2}{*}{ Husband aged $\geq 60$} & $0.34 * *$ & 0.010 \\
\hline & $(0.009)$ & $(0.008)$ \\
\hline \multirow[t]{2}{*}{ Wife aged $\geq 60$} & 0.003 & $0.26^{* *}$ \\
\hline & $(0.007)$ & $(0.009)$ \\
\hline \multicolumn{3}{|c|}{ Linear regression, linear polynomial in age \& interaction with the treatment dummy, couple random effects, bandwidth $48 \mathbf{m}$. } \\
\hline \multirow[t]{2}{*}{ Husband aged $\geq 60$} & $0.34 * *$ & 0.005 \\
\hline & $(0.005)$ & $(0.006)$ \\
\hline \multirow[t]{2}{*}{ Wife aged $\geq 60$} & 0.009 & $0.26^{* *}$ \\
\hline & $(0.005)$ & $(0.006)$ \\
\hline \multicolumn{3}{|c|}{ Linear regression, linear polynomial in age \& interaction with the treatment dummy, couple fixed effects, bandwidth $48 \mathbf{m}}$. \\
\hline \multirow[t]{2}{*}{ Husband aged $\geq 60$} & $0.34 * *$ & 0.03 \\
\hline & $(0.006)$ & $(0.007)$ \\
\hline \multirow[t]{2}{*}{ Wife aged $\geq 60$} & $0.01 *$ & $0.27 * *$ \\
\hline & $(0.006)$ & $(0.007)$ \\
\hline Number of observations & 40223 & 40223 \\
\hline Number of panel observations & 21595 & 21595 \\
\hline
\end{tabular}

Note: The model includes linear polynomials in the age (distance in months from age 60 at the date of the interview) for each spouse and a linear interaction of the dummy for being aged 60 and above with this polynomial for each spouse. The standard errors are adjusted and clustered at the couple level. Standard errors are given in brackets. In the table, $* *$ indicates statistical significance at the $5 \%$ level and $*$ indicates statistical significance at the $10 \%$ level. Here the bandwidth is set with respect to both spouses' being aged 60 or above. 
Figure A. Husband's and Wife's Own Retirement Probability at other legal (early-)retirement ages
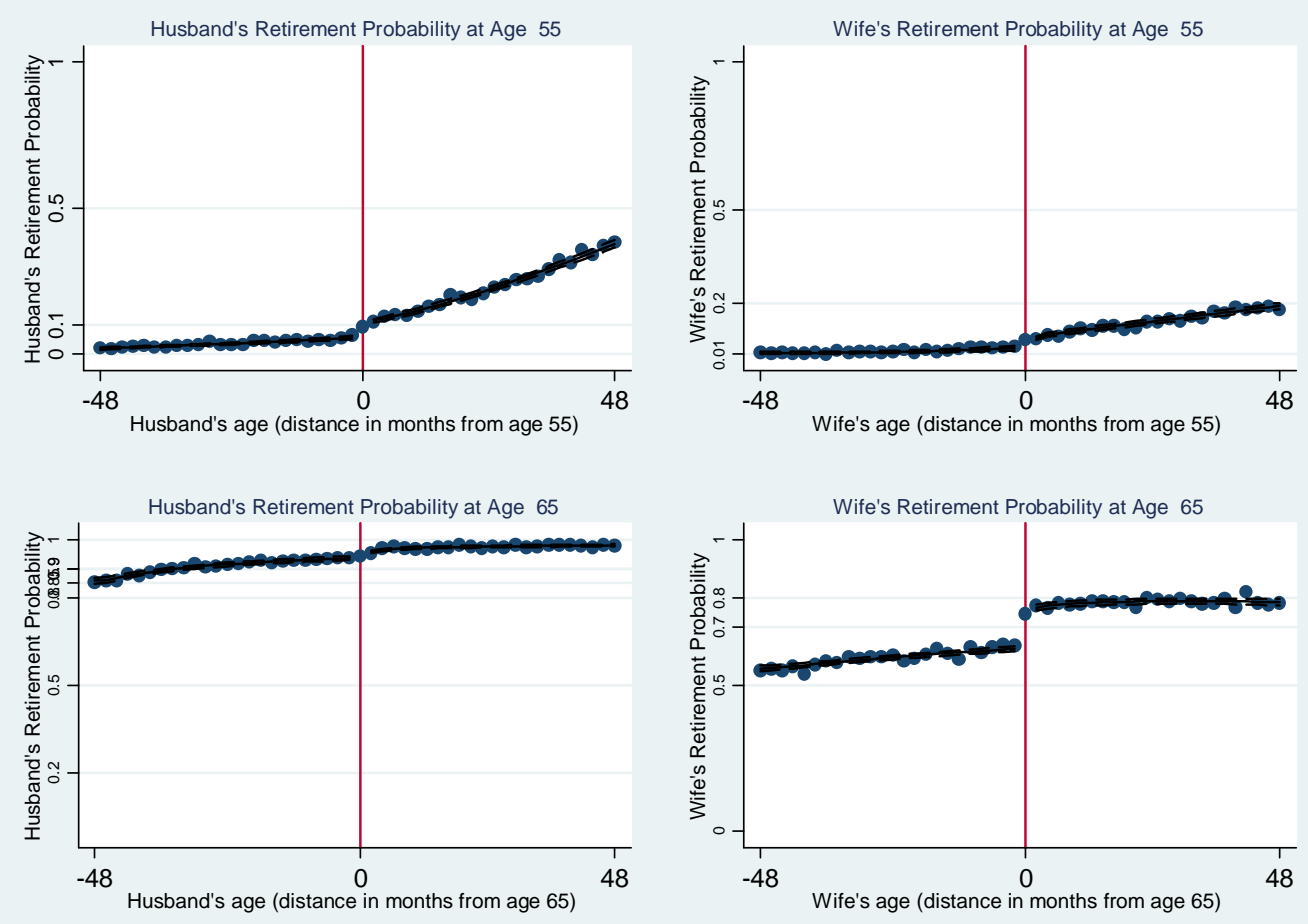

Note: The graphs show the retirement probability of the husband (left panel) and the wife (right panel) by own age. The age of "zero" corresponds, respectively, to the early retirement age of 55 (top panel) and to the legal retirement age of 65 (bottom panel). While 60 is the legal retirement age for most workers in France, 55 is the typical age at which special early-retirement programs may apply and 65 is the legal retirement age by which most workers are obliged to retire if they have not yet done so. The observations are grouped by bins of two months. The dots are the raw means of the outcome variable (the retirement probability) which is plotted against the running variable (distance in months from being aged, respectively, 55 or 65, when interviewed). Retirement status is also measured at the interview date. The solid line is non-parametrically fitted using a triangular kernel with a bandwidth of 48 months. The dotted lines are the 5 percent confidence bounds around the kernel estimates. Very few spouses retire at the early retirement age of 55: there is no discontinuity in retirement probabilities at age 55 for either husband or wife. By age 65, most husbands have already retired: there is no jump into retirement at age 65 for the husband. In contrast, although the average wife will have retired at age 60, we also observe a noticeable jump into retirement at age 65 , at least for some of the wives. 
Figure B. Husband's and Wife's Unemployment Probability at age 55 and 3 months
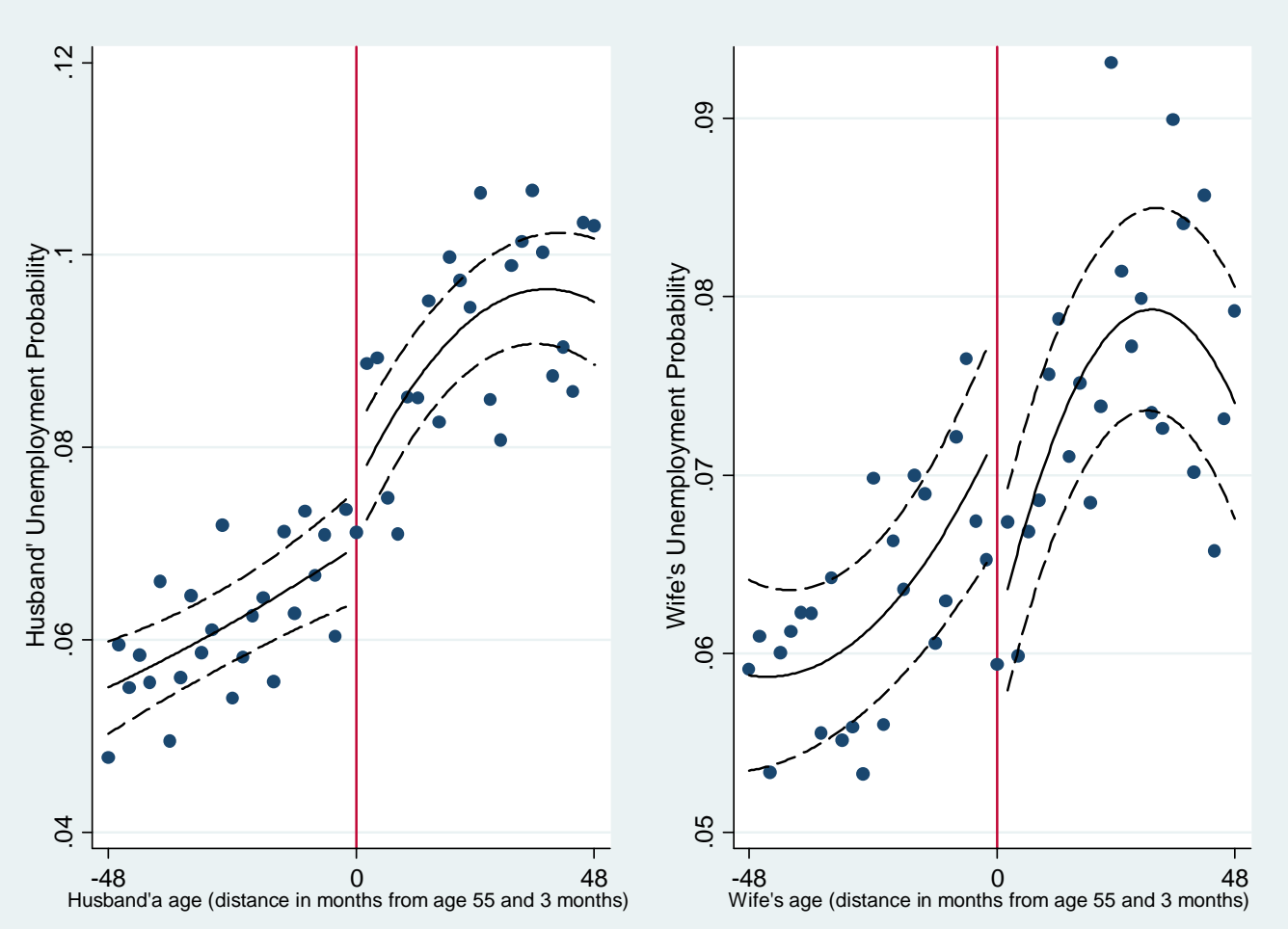

Note: The graphs show the unemployment probability of the husband (left graph) and the wife (right graph) by own age. The age of "zero" corresponds to the age of 55 and 3 months, at which individuals who are unemployed are dispensed from actively searching from work and their unemployment benefits are no longer regressive, so that they can make a smooth transition into retirement if needed. The observations are grouped by bins of two months. The dots are the raw means of the outcome variable (the unemployment probability) which is plotted against the running variable (distance in months from being aged 55 and 3 months when interviewed). The unemployment status is also measured at the interview date. The solid line is non-parametrically fitted using a triangular kernel with a bandwidth of 48 months. The dotted lines are the 5 percent confidence bounds around the kernel estimates. 
Table D. Descriptives statistics of the sample of couples with both spouses aged 50 to 70 .

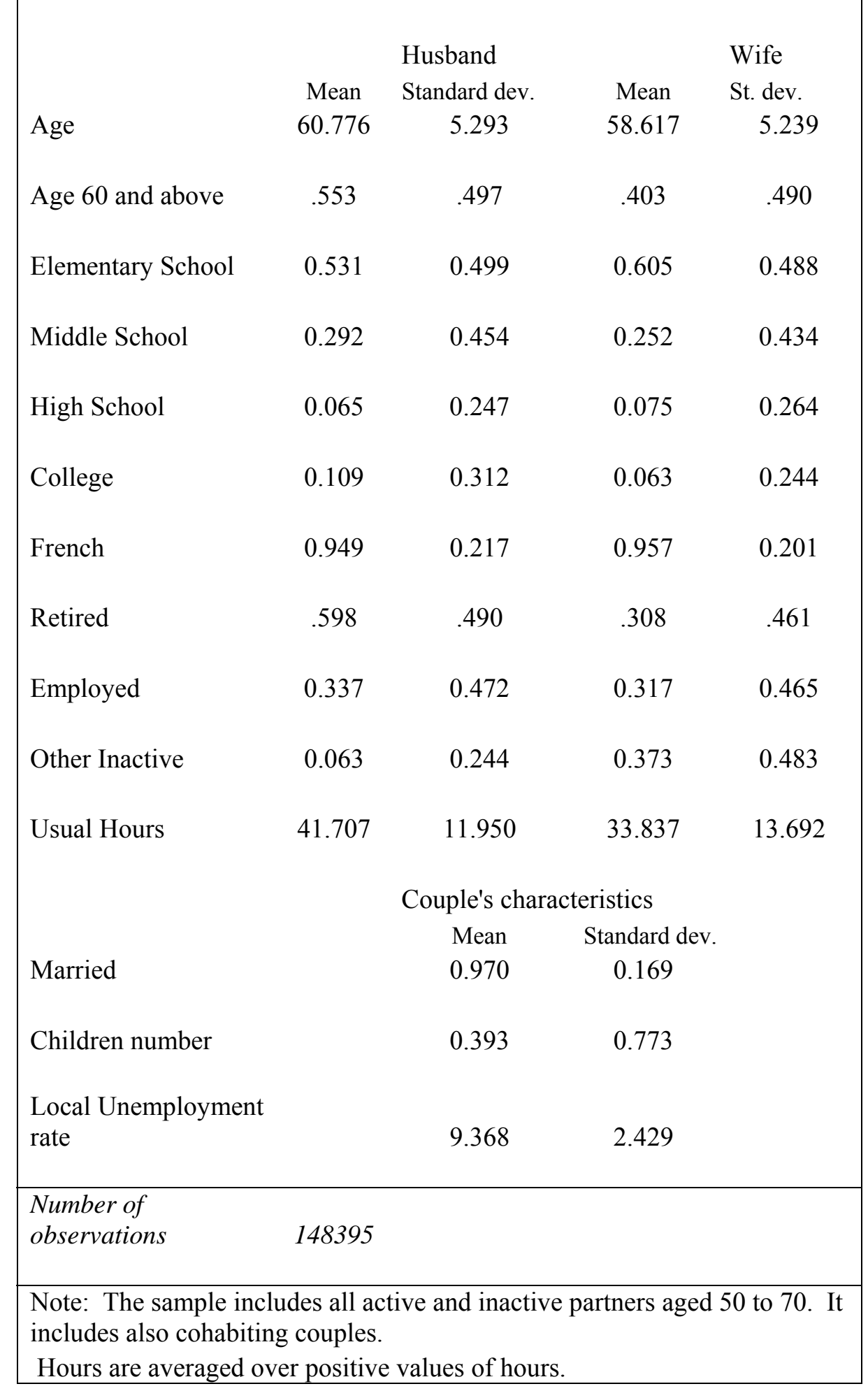


TableE. Reasons to retire (multiple answers are possible): \%

\begin{tabular}{|c|c|c|c|c|}
\hline & Very Important & Important & $\begin{array}{l}\text { Minor } \\
\text { reason }\end{array}$ & $\begin{array}{l}\text { Not at all } \\
\text { relevant }\end{array}$ \\
\hline \multicolumn{5}{|l|}{ Retirement Rights reasons } \\
\hline $\begin{array}{l}\text { You can still continue to work or take up a new } \\
\text { job }\end{array}$ & 11 & 11 & 9 & 69 \\
\hline You turned 60 years of age & 37 & 14 & 5 & 44 \\
\hline $\begin{array}{l}\text { You reached the age at which you could retire } \\
\text { with the highest possible retirement pension. }\end{array}$ & 49 & 22 & 5 & 24 \\
\hline \multicolumn{5}{|l|}{ Job related reasons } \\
\hline You were dismissed or forced to retire & 9 & 3 & 2 & 86 \\
\hline $\begin{array}{l}\text { Your employer or colleagues were pushing you } \\
\text { to retire one way or other }\end{array}$ & 12 & 8 & 6 & 73 \\
\hline You were unhappy with the job conditions & 12 & 9 & 7 & 72 \\
\hline $\begin{array}{l}\text { You had health problems that hindered your } \\
\text { work capacities }\end{array}$ & 15 & 8 & 6 & 71 \\
\hline You had had enough of your job & 23 & 17 & 10 & 50 \\
\hline \multicolumn{5}{|l|}{ Personal and Family reasons } \\
\hline You had family obligations & 7 & 7 & 4 & 81 \\
\hline $\begin{array}{l}\text { Your spouse was also retiring or had already } \\
\text { retired }\end{array}$ & 12 & 6 & 3 & 78 \\
\hline You had other personal projects & 7 & 12 & 8 & 72 \\
\hline $\begin{array}{l}\text { You wanted to take advantage of being retired as } \\
\text { long as possible }\end{array}$ & 47 & 21 & 7 & 26 \\
\hline
\end{tabular}

Note: Each row sums up to $100 \%$. The sample is a representative sample of French retirees who entered retirement from employment. The respondent could indicate multiple reasons.

Source: Enquête Motivations de départ à la retraite 2010, CNAV-COR-DARES-DGT-DREES-DSS. 